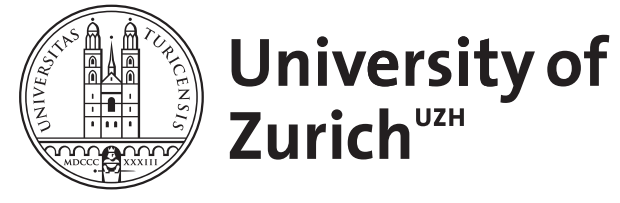

\title{
Early, goal-directed resuscitation for septic shock
}

\author{
Auinger, Katja ; Maggiorini, Marco
}

\begin{abstract}
The Protocolised Management in Sepsis (ProMISe) trial (April 2 issue) completes a trio of studies that question the further application of early, goal-directed therapy (EGDT) as suggested by Rivers et al. In particular, these trials consistently show no survival benefit with regard to the mandated use of central venous oxygen saturation $\left(\mathrm{ScvO}_{2}\right)$ monitoring. However, it remains questionable whether the results of the three trials support this claim. According to the EGDT protocol, an $\mathrm{ScvO}_{2}$ value of less than $70 \%$ is a trigger for hemodynamic intervention. Unlike in the study by Rivers et al., the reported mean values at baseline in all three trials do not require any intervention. Whether the reported survival benefit in the study by Rivers et al. is based on the treatment of patients with initially extremely low $\mathrm{ScvO}_{2}$ values and determines the targeted patient population that benefits from EGDT remains, therefore, unanswered. Pope et al. reported increased mortality when $\mathrm{ScvO}_{2}$ values were initially low $(<70 \%)$ or high $(>80 \%)$. Unless subgroup analyses and further studies that focus on these high-risk patients do not rule out a survival benefit, the final conclusion of the three trials cannot be supported.
\end{abstract}

DOI: https://doi.org/10.1056/NEJMc1506514SA1

Posted at the Zurich Open Repository and Archive, University of Zurich ZORA URL: https://doi.org/10.5167/uzh-122557

Journal Article

Published Version

Originally published at:

Auinger, Katja; Maggiorini, Marco (2015). Early, goal-directed resuscitation for septic shock. New England Journal of Medicine, 373(6):576.

DOI: https://doi.org/10.1056/NEJMc1506514SA1 


\section{O R R E S P O N D N C E}

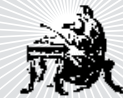

\section{Early, Goal-Directed Resuscitation for Septic Shock}

TO THE EDITOR: The Protocolised Management in Sepsis (ProMISe) trial (April 2 issue) ${ }^{1}$ completes a trio of studies ${ }^{1-3}$ that question the further application of early, goal-directed therapy (EGDT) as suggested by Rivers et al. ${ }^{4}$ In particular, these trials consistently show no survival benefit with regard to the mandated use of central venous oxygen saturation $\left(\mathrm{ScvO}_{2}\right)$ monitoring. However, it remains questionable whether the results of the three trials support this claim. According to the EGDT protocol, an $\mathrm{ScvO}_{2}$ value of less than $70 \%$ is a trigger for hemodynamic intervention. Unlike in the study by Rivers et al., the reported mean values at baseline in all three trials do not require any intervention. Whether the reported survival benefit in the study by Rivers et al. is based on the treatment of patients with initially extremely low $\mathrm{ScvO}_{2}$ values and determines the targeted patient population that benefits from EGDT remains, therefore, unanswered. Pope et al. ${ }^{5}$ reported increased mortality when $\mathrm{ScvO}_{2}$ values were initially low $(<70 \%)$ or high $(>80 \%)$. Unless subgroup analyses and further studies that focus on these high-risk patients do not rule out a sur-

\section{THIS WEEK'S LETTERS}

576 Early, Goal-Directed Resuscitation for Septic Shock

578 Rociletinib in EGFR-Mutated Non-Small-Cell Lung Cancer

579 Everolimus-Eluting Stents or Bypass Surgery for Coronary Disease

582 PML in Patients Treated with Dimethyl Fumarate

584 MYD88 Mutations and Response to Ibrutinib in Waldenström's Macroglobulinemia vival benefit, the final conclusion of the three trials cannot be supported.

Katja Auinger, M.D.

Marco Maggiorini, M.D.

University Hospital Zurich

Zurich, Switzerland

katja.auinger@usz.ch

No potential conflict of interest relevant to this letter was reported.

1. Mouncey PR, Osborn TM, Power GS, et al. Trial of early, goal-directed resuscitation for septic shock. N Engl J Med 2015; 372:1301-11.

2. The ProCESS Investigators. A randomized trial of protocolbased care for early septic shock. N Engl J Med 2014;370:168393.

3. The ARISE Investigators and the ANZICS Clinical Trials Group. Goal-directed resuscitation for patients with early septic shock. N Engl J Med 2014;371:1496-506.

4. Rivers E, Nguyen B, Havstad S, et al. Early goal-directed therapy in the treatment of severe sepsis and septic shock. N Engl J Med 2001;345:1368-77.

5. Pope JV, Jones AE, Gaieski DF, Arnold RC, Trzeciak S, Shapiro NI. Multicenter study of central venous oxygen saturation $(\mathrm{ScvO}(2))$ as a predictor of mortality in patients with sepsis. Ann Emerg Med 2010;55:40-6.

DOI: 10.1056/NEJMc1506514

TO THE EDITOR: The ProMISe trial investigators report that EGDT did not reduce 90-day mortality among patients with early septic shock. Fluid therapy is crucial in EGDT. By 72 hours, approximately $40 \%$ of the study patients had received a median of 1.0 liter of intravenous colloids, and $98 \%$ of the patients had received a median of 4.9 liters of intravenous crystalloids (Table S7 in the Supplementary Appendix of the article, available with the full text of the article at NEJM.org). The values for the interquartile range indicate that individual patients had received considerably larger amounts. Similar amounts of fluids in the treatment of early septic shock have been shown to increase mean serum chloride concentrations from $100 \mathrm{mmol}$ per liter initially to 106 to 108 
mmol per liter during the first 72 hours, ${ }^{1}$ probably related to the use of hyperchloremic solutions. Such solutions are well known to be associated with numerous adverse outcomes. ${ }^{2,3}$ Red-cell transfusion is also associated with worse outcomes, including those in critically ill patients. ${ }^{4}$ Because the use of hyperchloremic solutions and blood transfusions might have obscured potential treatment effects, information regarding types of fluids, serum chloride concentrations, and the reason for the significantly higher frequency of red-cell transfusions in the EGDT group than in the usual-care group is required.

Hans-Joachim Priebe, M.D.

University Hospital Freiburg

Freiburg, Germany

hans-joachim.priebe@uniklinik-freiburg.de

No potential conflict of interest relevant to this letter was reported.

1. The ProCESS Investigators. A randomized trial of protocolbased care for early septic shock. N Engl J Med 2014;370:168393.

2. Yunos NM, Bellomo R, Hegarty C, Story D, Ho L, Bailey M. Association between a chloride-liberal vs chloride-restrictive intravenous fluid administration strategy and kidney injury in critically ill adults. JAMA 2012;308:1566-72.

3. Krajewski ML, Raghunathan K, Paluszkiewicz SM, Schermer CR, Shaw AD. Meta-analysis of high- versus low-chloride content in perioperative and critical care fluid resuscitation. Br J Surg 2015;102:24-36.

4. Marik PE, Corwin HL. Efficacy of red blood cell transfusion in the critically ill: a systematic review of the literature. Crit Care Med 2008;36:2667-74.

DOI: 10.1056/NEJMc1506514

TO THE EDItor: The ProMISe trial, the Australasian Resuscitation in Sepsis Evaluation (ARISE) trial, and the Protocolized Care for Early Septic Shock (ProCESS) trial suggest no additional benefit from hemodynamic management with strict EGDT, characterizing EGDT only as a hemodynamic study. In addition to hemodynamic monitoring from the EGDT component, the Surviving Sepsis Campaign (SSC) guidelines ${ }^{1}$ include early detection of high-risk patients with the use of the criteria of the systemic inflammatory response syndrome, the shock index (ratio of heart rate to systolic blood pressure), and measurement of serum lactate levels. EGDT has played a central role in the development of current tenets of shock management. In the triad of randomized, controlled trials, each component of EGDT was applied in all groups except monitoring of central venous pressure and $\mathrm{ScvO}_{2}$, and they were pro- vided in more than $50 \%$ of the participants in the usual-care groups. Mortality decreased in both control and intervention groups by more than $50 \%$ - a greater degree than in previous trials. These results strongly support the pivotal role of the SSC guidelines that include EGDT. ${ }^{1-3}$ Although these trials reveal that monitoring of central venous pressure is not mandatory, they show no harm in EGDT and certainly do not suggest that other aspects of the guidelines be called into question. We are concerned that the conclusions promulgated by the triad of trials will be misinterpreted and will cast doubt on the importance of SSC protocols for sepsis detection and treatment.

Sharad Manaktala, M.D., Ph.D.

Stephen R. Claypool, M.D.

Wolters Kluwer Health

Minneapolis, MN

steve.claypool@wolterskluwer.com

Drs. Claypool and Manaktala report being paid employees of Wolters Kluwer Health, which provides decision support for sepsis. No other potential conflict of interest relevant to this letter was reported.

1. Dellinger RP, Levy MM, Rhodes A, et al. Surviving Sepsis Campaign: international guidelines for management of severe sepsis and septic shock, 2012. Intensive Care Med 2013;39:165228.

2. Rivers E, Nguyen B, Havstad S, et al. Early goal-directed therapy in the treatment of severe sepsis and septic shock. N Engl J Med 2001;345:1368-77.

3. Levy MM, Rhodes A, Phillips GS, et al. Surviving Sepsis Campaign: association between performance metrics and outcomes in a 7.5-year study. Intensive Care Med 2014;40:1623-33.

DOI: 10.1056/NEJMc1506514

THE AUthors RePly: Auinger and Maggiorini suggest that the ProCESS, ${ }^{1}$ ARISE, ${ }^{2}$ and ProMISe trials reported mean $\mathrm{ScvO}_{2}$ values at baseline that are considerably higher than those in both the EGDT group and the usual-care group in the study by Rivers et al. ${ }^{3}$ The values to which they refer for the EGDT groups in the three trials, however, are not baseline values and are typically from at least 1 hour postrandomization (after insertion of the catheter with $\mathrm{ScvO}_{2}$ monitoring capability). The values in the study by Rivers et al. are prerandomization (all patients received catheters with $\mathrm{ScvO}_{2}$ monitoring capability before randomization in this study), and, therefore, the comparison is not valid. Subgroup analyses of high-risk patients in the three multicenter trials, using illness-severity scores, serum lactate concentrations, or both as proxies for baseline 
$\mathrm{ScvO}_{2}$ (because $\mathrm{ScvO}_{2}$ data were not available for the usual-care groups), showed no evidence of benefit.

We agree with Priebe that administration of intravenous isotonic saline solutions can cause hyperchloremia and acidosis. In the ProMISe trial, although we did not record the type of crystalloid administered or the serum chloride level, the volume of crystalloid administered by 72 hours after randomization was similar in the EGDT and usual-care groups, and it is likely that, on average, the fluids used were the same in the two groups. With respect to red-cell transfusions, the evidence base is conflicting, with more recent data ${ }^{4,5}$ indicating no evidence of harm caused by transfusions.

Manaktala and Claypool are concerned about misinterpretation of the results of the ProCESS, ARISE, and ProMISe trials. With interpretation in mind, we stated in the Conclusions section of the abstract of our article that "in patients with septic shock who were identified early and received intravenous antibiotics and adequate fluid resuscitation, hemodynamic management according to a strict EGDT protocol did not lead to an improvement in outcome."

Paul R. Mouncey, M.Sc.

G. Sarah Power, M.Sc.

Intensive Care National Audit and Research Centre London, United Kingdom

Timothy J. Coats, M.D.

University of Leicester

Leicester, United Kingdom

Since publication of their article, the authors report no further potential conflict of interest.

1. The ProCESS Investigators. A randomized trial of protocolbased care for early septic shock. N Engl J Med 2014;370:1683-93.

2. The ARISE Investigators and the ANZICS Clinical Trials Group. Goal-directed resuscitation for patients with early septic shock. N Engl J Med 2014;371:1496-506.

3. Rivers E, Nguyen B, Havstad S, et al. Early goal-directed therapy in the treatment of severe sepsis and septic shock. $\mathrm{N}$ Engl J Med 2001;345:1368-77.

4. Lacroix J, Hébert PC, Fergusson DA, et al. Age of transfused blood in critically ill adults. N Engl J Med 2015;372:1410-8.

5. Murphy GJ, Pike K, Rogers CA, et al. Liberal or restrictive transfusion after cardiac surgery. N Engl J Med 2015;372:997-1008.

DOI: 10.1056/NEJMc1506514

\section{Rociletinib in EGFR-Mutated Non-Small-Cell Lung Cancer}

TO THE EDITOR: Sequist et al. (April 30 issue) ${ }^{1}$ report that rociletinib can overcome the resistance to epidermal growth factor receptor (EGFR) tyrosine kinase inhibitors in patients with non-smallcell lung cancer (NSCLC) harboring the EGFR T790M resistance mutation. Rociletinib treatment was associated with significantly longer progression-free survival among such patients than among patients not harboring these mutations. We noted that of the 92 study patients who received therapeutic doses of rociletinib, 35 (38\%) also received glucose-lowering therapy (typically metformin) to treat hyperglycemia.

Metformin, an antidiabetic drug, has been shown to exert anticancer activity. Lin et al. reported that metformin administration is associated with improved survival among patients with stage IV NSCLC with diabetes. ${ }^{2}$ Our study showed that metformin sensitizes NSCLC cells that are resistant to EGFR tyrosine kinase inhibitors. ${ }^{3}$ Furthermore, metformin suppresses the expression of the main detoxification enzyme, cytochrome P-450 3A4. ${ }^{4}$ Therefore, it could theoretically elevate plasma concentrations of rociletinib. These effects raise the possibility that metfor- min may have affected the results of the study by Sequist et al. I would like to know whether the patients who received rociletinib and metformin had better outcomes than those who received rociletinib only.

Yong He, Ph.D., M.D.

Daping Hospital of the Third Military Medical University Chongqing, China heyong8998@126.com

No potential conflict of interest relevant to this letter was reported.

1. Sequist LV, Soria JC, Goldman JW, et al. Rociletinib in EGFRmutated non-small-cell lung cancer. N Engl J Med 2015;372: 1700-9.

2. Lin JJ, Gallagher EJ, Sigel K, et al. Survival of patients with stage IV lung cancer with diabetes treated with metformin. Am J Respir Crit Care Med 2015;191:448-54.

3. Li L, Han R, Xiao H, et al. Metformin sensitizes EGFR-TKIresistant human lung cancer cells in vitro and in vivo through inhibition of IL-6 signaling and EMT reversal. Clin Cancer Res 2014;20:2714-26.

4. Krausova L, Stejskalova L, Wang H, et al. Metformin suppresses pregnane $\mathrm{X}$ receptor (PXR)-regulated transactivation of CYP3A4 gene. Biochem Pharmacol 2011;82:1771-80.

DOI: 10.1056/NEJMc1506831

THE AUTHORS REPLY: We agree that some evidence suggests that metformin has intrinsic anticancer 